\title{
Developing Suitable Proportions for the Production of Pineapple Leaf Fibers Reinforced Normal Strength Concrete
}

\author{
Kayibanda Patrick ${ }^{1}$, Richard Ocharo Onchiri ${ }^{2}$, Geoffrey N. Mang'uriu ${ }^{3}$ \\ ${ }^{1}$ Department of Civil and Construction Engineering, Institute for Basic Sciences, Technology and Innovation, Pan African \\ University, Nairobi, Kenya \\ ${ }^{2}$ Department of Building and Civil Engineering, Technical University of Mombasa, Mombasa, Kenya \\ ${ }^{3}$ Department of Civil, Construction and Environmental Engineering, Jomo Kenyatta University of Agriculture and Technology, \\ Nairobi, Kenya \\ Email: ^kydpatrick@gmail.com
}

How to cite this paper: Patrick, K., Onchiri, R.O. and Manguriu, G. (2019) Developing Suitable Proportions for the Production of Pineapple Leaf Fibers Reinforced Normal Strength Concrete. Open Journal of Civil Engineering, 9, 185-194.

https://doi.org/10.4236/ojce.2019.93013

Received: June 13, 2019

Accepted: July 6, 2019

Published: July 9, 2019

Copyright (c) 2019 by author(s) and Scientific Research Publishing Inc. This work is licensed under the Creative Commons Attribution International License (CC BY 4.0).

http://creativecommons.org/licenses/by/4.0/

\begin{abstract}
The present work tried to develop suitable proportions for the production of Pineapple Leaf Fibers (PALF) reinforced Normal Strength Concrete (NSC), an experimental analysis with a mix ratio of 1:1.84:3.27 for cement: fine aggregates: coarse aggregates with constant water to cement ratio of 0.54 . The total volume per mixing batch was calculated of 9 cubes +9 cylinders +3 beams in order to know the number of materials to be used in casting per batch, and the PALF percentage was taken based on cement weight whereby it starts from the lowest to the maximum as follow $0 \%, 0.2 \%, 0.4 \%, 0.6 \%$, $0.8 \%$, and $1 \%$. The tests that were done on fresh concrete were compacting factors and workability using the slump test which was carried out on each fresh mix of concrete. The results showed that PALF can be used to improve the Tensile and Flexural properties of Normal Strength Concrete.
\end{abstract}

\section{Keywords}

Pineapple Leaf Fibers, Tensile Strength, Compressive Strength, Flexural Strength, and Water Absorption

\section{Introduction}

The construction industry is one of rapidly growing industries across the world. In this industry, concrete plays an inherent role and is the most widely used manmade construction material. Concrete will continue to be the leading construction material all over the world due to its versatile advantageous properties 
such as good compressive strength, and high mould ability, plastic and malleable when fresh and durable, impermeable and fire resistant when hardened [1] [2]. Concrete is therefore used for advanced applications, design and construction techniques such as building houses, bridges, dams, pavements, stadiums, retaining structures, airports and skyscrapers. However, NSC has some undesirable properties like being weak in tension, brittleness, less resistance to cracking, low impact resistance and heavy weight, hence there is a need to improve the concrete properties [3] [4]. Pineapple Leaf Fibers (PALF) are more compatible natural fiber resource and constitutes a good chemical composition [5]. PALF are a vital natural fiber, which have a high specific strength, rigidity, flexural and torsional rigidity than other fibers; seen all these advantages of PALF and since no one has developed suitable proportion of production of PALF reinforced on NSC it is time to try such fiber. Natural fibers have the advantages of low density, low cost, and biodegradability. When concrete cracks, the randomly oriented fibers start functioning, arrest crack formation and propagation, and thus improve strength and ductility. Natural fibres from pineapple leaves are a good option to study because of their high tensile strength and high cellulose content [6]. The use of PALF reinforcement in construction materials can enhance structural strength and toughness, and this can reduce cracking and shrinkage [7]. Hence this study was made to develop a suitable proportion of production of PALF on properties of NSC.

\section{Materials and Methods}

The methods adopted and followed for this study are discussed in the subsequent section. The most important test methods and standards are summarized in Table 1, The materials used in this study were coarse aggregates, fine aggregates, Ordinary Portland Cement (OPC) grade of (42.5 N) East African Standard KS EAS 18.1 was used in the study and water, all of them were collected from Kenya. The PALF materials were obtained from Hand Conifer Company Ltd, Mumbai, India. The fibres were extracted from the leaves by using a mechanical extractor machine [8]. Coarse aggregates were obtained locally and those conforming to BS EN 109-1 specification and limited to a maximum size of $25 \mathrm{~mm}$

Table 1. Test methods adopted.

\begin{tabular}{cccc}
\hline \multicolumn{4}{c}{ Test on Constituent materials of NSC Test on fresh and hardened NSC with PALF } \\
\hline Test Performed & Standard Used & Test Performed & Standard Used \\
Sieve Analysis & BS EN 109-1 & Slump & BS EN 12350-2 \\
Aggregate specific gravity & BS EN 1097-6 & Compacting Factor & BS 1881-103 \\
Fineness modulus & ASTM C136 & Water absorption & BS EN 12350-3 \\
Cement Specific Gravity & BS EN 197-1 & Compressive strength & BS EN 12390-3 \\
Aggregate water absorption & BS EN 1097-6 & Split tensile strength & BS EN 12390-6 \\
Consistency \& Setting Time of Cement & BS EN 197-1 & Flexural strength & BS EN 12390-7 \\
\hline
\end{tabular}


were used. They were first washed to remove the dust and dirt, and then dried to surface dry condition before use in the mix. The fine aggregates used was river sand obtained locally from Meru, in Kenya and was then sieved through a 10 $\mathrm{mm}$ sieve to remove any coarse particle before use. The materials were batched by weight at a ratio of 1:1.84:3.27 with respect to OPC: fine aggregates: coarse aggregates with a constant water/cement ratio of 0.54 , they were then mixed and after PALF were added to the mix at percentages of $0 \%, 0.2 \%, 0.4 \%, 0.6 \%, 0.8 \%$, and $1 \%$ of cement weight and finally water added to form a paste. On each fresh mix of concrete both workability was determined using the slump test and compacting factor was determined using two conical hoppers having a hinged trap door attached to the lower end of each hopper, allowing the concrete sample to flow freely into the cylindrical mould in accordance with BS EN 12390-6. The mixture was then cast into greased cubes of $150 \times 150 \times 150 \mathrm{~mm}$, cylinders of $150 \mathrm{~mm}$ diameter and $300 \mathrm{~mm}$ height and beams of and then compacted using a poker vibrator after which was left to set for 24 hours and then demoulded and placed in curing tanks for 7 days, 14 days and 28 days of curing period [9] [10]. The concrete cubes, the cylinders and beams were tested for compressive strength, splitting tensile strength and flexural strength using the universal testing machine at 7 days, 14 days and 28 days in accordance with European Standards of BS EN 12390-3 and Water absorption at 28 days accordance to BS EN 12350-3.

\section{Material Characterization}

\subsection{Coarse and Fine Aggregates}

The fine aggregates used was river sand sieved on a $10 \mathrm{~mm}$ BS sieve to remove any coarse particles and the fine aggregates were ranging from $0.15 \mathrm{~mm}(150$ $\mu \mathrm{m})$ to $10 \mathrm{~mm}$. The coarse aggregates used were crushed angular shaped rocks ranging from $2.36 \mathrm{~mm}$ to $25 \mathrm{~mm}$. Table 2 shows the physical properties of both the coarse aggregates and the fine aggregates that were carried out. From these results, the conclusion was made that both aggregates satisfied the standards and therefore could be used in the production of Normal weight concrete reinforced with PALF.

Table 2. Physical properties of coarse and fine aggregates.

\begin{tabular}{ccc}
\hline Properties & Fine aggregates & Coarse aggregates \\
\hline Particle size & $0.15 \mathrm{~mm}-5 \mathrm{~mm}$ & $2.36 \mathrm{~mm}-25 \mathrm{~mm}$ \\
Specific gravity & $2.67 \mathrm{~g} / \mathrm{cm}^{3}$ & $2.78 \mathrm{~g} / \mathrm{cm}^{3}$ \\
Water absorption & $5.78 \%$ & $2.25 \%$ \\
shape & - & Angular \\
Surface texture & - & Rough \\
Moisture content & $2.21 \%$ & $2.06 \%$ \\
Fineness modulus & $2.41 \%$ & - \\
\hline
\end{tabular}

Source: BS EN 109-1. 


\subsection{Ordinary Portland Cement (OPC) I $42.5 \mathrm{~N}$}

Table 3 shows the physical properties of the cement used in the study as compared to the requirement as per BS EN 197-1 Methods of physical tests for hydraulic cement (Determination of consistency of standard cement paste).

\subsection{Pineapple Leaf Fibers}

PALF were treated in $4 \%$ of Sodium Hydroxide Before chemical properties analysis and tensile strength of PALF $(\mathrm{NaOH})$ solution over various duration $\mathrm{NaOH}$ is one of the best treatment of natural fibers, in increasing fibers roughness by chemically modifying and cleaning the fibre surface [11] [12]. Table 4 shows the chemical properties that were determined. In this way, three containers (dishes) were put in oven dry for 10 minutes to be cool. The three samples were ready for the experiment, after that, they were weighted. The samples of PALF were added on the three dishes and weighted. To calculate the moisture content it was necessary to put them in oven dry for 3 hours, and then after weighing them to see the weight after drying our 3 samples. In accordance with ASTM D854-9 the PALF were cut in equal length of $30 \mathrm{~mm}$ and $0.052 \mathrm{~mm}$ of diameter.

Wt. A = weight after $12 \mathrm{~h}$ of even dry $40^{\circ} \mathrm{C}$ using $\mathrm{C}_{2} \mathrm{H}_{5} \mathrm{OH}$

Wt. $\mathrm{B}=$ weight after $12 \mathrm{~h}$ of even dry $80^{\circ} \mathrm{C}$ using $\mathrm{KOH}$

Wt. $\mathrm{C}=$ weight after $12 \mathrm{~h}$ of even dry $80^{\circ} \mathrm{C}$ using $\mathrm{H}_{2} \mathrm{SO}_{4}$

Table 3. Physical properties of ordinary Portland cement.

\begin{tabular}{ccc}
\hline Properties & Description & Requirement as per EN197-1 \\
\hline Standard consistency & $31.5 \%$ & $26 \%$ to $33 \%$ \\
Specific gravity & 3.14 & 3.1 to $3.16 \mathrm{~g} / \mathrm{cm}^{3}$ \\
Initial Setting Time & $138 \mathrm{~min}$ & Not less than $60 \mathrm{~min}$ \\
Final Setting Time & $229 \mathrm{~min}$ & Not more than $600 \mathrm{~min}$ \\
Soundness & $0.8 \mathrm{~mm}$ & Not more than $10 \mathrm{~mm}$ \\
Color & Grey & - \\
Specific gravity & 3.14 & 3.1 to $3.16 \mathrm{~g} / \mathrm{cm}^{3}$ \\
\hline
\end{tabular}

Source: BS EN 197-1.

Table 4. Chemical properties of PALF.

\begin{tabular}{|c|c|c|c|c|c|c|c|c|c|}
\hline sample & smp wt & glass wt & glass + smp & wt. A & wt. B & wt. C & cellulose & hemicellulose & lignin \\
\hline A & 1.007 & 31.7241 & 32.7311 & 32.8743 & 32.5838 & 32.2444 & 33.704 & 28.848 & 32.2444 \\
\hline B & 1.009 & 31.9622 & 32.9712 & 33.1588 & 32.8394 & 32.4612 & 37.483 & 31.655 & 32.4612 \\
\hline \multirow[t]{3}{*}{$\mathrm{C}$} & 1.004 & 31.3027 & 32.3067 & 32.5025 & 32.2354 & 31.9047 & 32.898 & 26.643 & 31.9047 \\
\hline & & & & & & mean & 34.695 & 30.252 & 32.353 \\
\hline & & & & & & stdev & 2.672 & 2.512 & 0.281 \\
\hline
\end{tabular}

Source: The chemical properties (i.e., proportions of cellulose, hemicellulose and lignin) of the treated four (4) fibers samples were determined based the procedure described by Direct method of cellulose, hemicelluloses and lignin [6] [13]. 


\subsection{Water}

Water Ordinary portable water conforming to BS 1348-2 (1980) available in the laboratory with a $\mathrm{pH}$ of 8.1 was used in the study for mixing and curing of concrete mixes.

\section{Results and Discussion}

\subsection{Workability of Normal Strength Concrete with PALF}

Determination of workability in this study was done by the slump test which was carried out in triplicate on every mix that was made and an average value obtained. Results of the slump test are presented in Figure 1 showing the average slump for each mix versus the percentage addition of PALF in the mix [14].

Considering a constant water/cement ratio of 0.54 which was used in the mix design, as seen from Figure 1, as the content of PALF was increased in the mix, there was a reduction in the workability levels as reported by a reduction in the slump values from $65 \mathrm{~cm}$ for normal concrete at percentage reductions of $7.69 \%$, $15.38 \%, 20 \%, 38.46 \%$, and $61.53 \%$ for $0.2 \%, 0.4 \%, 0.6 \%, 0.8 \%$ and $1 \%$ PALF addition respectively as compared to the control. As there was a reduction in the slump with the addition of PALF in the mix, the concrete remained workable in nature. This reduction in a slump of concrete was attributed to the presence of fibers in the mix as they lump on each other reducing the slump while the mixture is still workable. Also, a reduction in the workability of fresh concrete may be caused by an adhesion within the concrete and holding the other ingredients of concrete together impeding easy flow. Therefore the mix required more compacting effort to achieve proper compaction as this would directly affect the density, strength, water absorption and hence the durability of the hardened concrete.

\subsection{Water Absorption of Normal Strength Concrete with PALF}

As portrayed in Figure 2, PALF incorporation in the concrete mix increased the water absorption of the mixes as the control had the least water absorption whereas there was a subsequent increment as the PALF were increased in the mix.

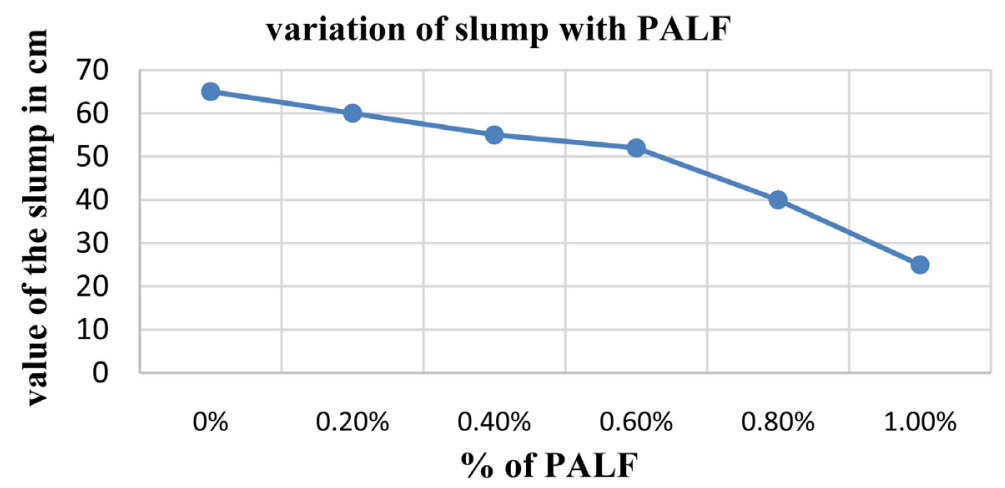

Figure 1. Variation of a slump with PALF. 


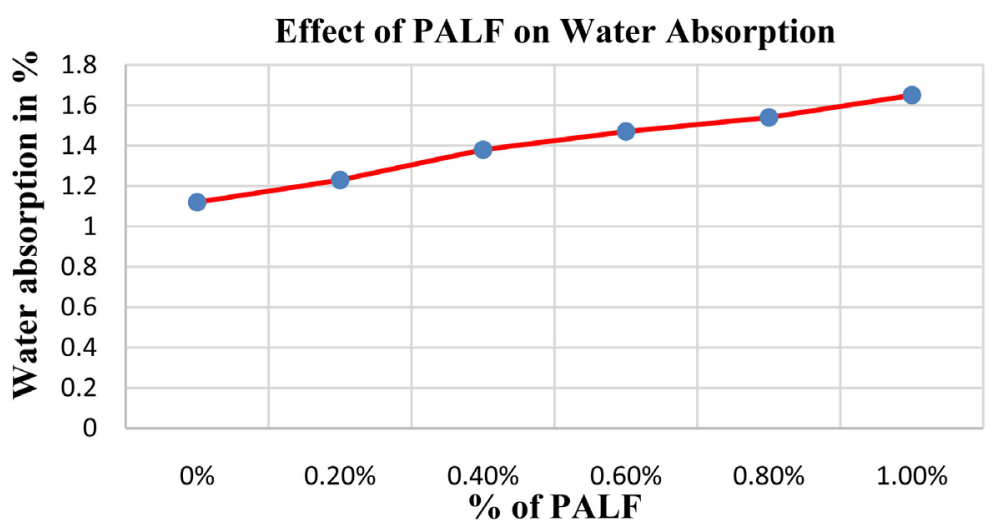

Figure 2. Effect of PALF on water absorption.

PALF added at percentages of $0.2 \%, 0.4 \%, 0.6 \%, 0.8 \%$ and $1 \%$ had a percentage increase in the water absorption of $9.82 \%, 23.21 \%, 31.25 \%, 37.50 \%$ and $47.32 \%$ respectively as compared to the control mix ( $0 \% \mathrm{PALF})$. The increment in water absorption as the PALF are increased could be as a result of the poor compaction leading to poor bonding as a result of the smooth texture of the fibers and this increased the number of pores in the concrete specimen causing it to absorb more water.

\subsection{Compressive Strength of Normal Strength Concrete with PALF}

Compressive Strength of concrete with PALF [15] a reduction in compressive strength was recorded for both the 7 days, 14 days and 28 days though there was an increase in compressive strength with curing time as 28 days compressive strength values were greater than those at 7 days and 14 days curing. Percentage reductions of $3.07 \%, 4.21 \%, 6.19 \%, 9.14 \%$, and $11.60 \%$ at $0.2 \%, 0.4 \%, 0.6 \%, 0.8 \%$ and $1 \%$ PALF additions respectively were obtained as compared to the control mix at 7 days testing, where as $1.81 \%, 2.47 \%, 3.24 \%, 3.87 \%$, and $9.59 \%$ at $0.2 \%$, $0.4 \%, 0.6 \%, 0.8 \%$ and $1 \%$ PALF additions respectively as compared to the control mix were obtained at 14 days testing, where as $1.72 \%, 2.37 \%, 3.01 \%, 3.82 \%$ and $5.48 \%$ percentage reductions at $0.2 \%, 0.4 \%, 0.6 \%, 0.8 \%$ and $1 \%$ PALF additions respectively were obtained as compared to the control mix at 28 days curing time. From these results (Figure 3 ) it can be seen that PALF addition had the less percentage reduction in compressive strength compared to normal strength concrete and therefore it offers better compressive strength properties as compared to other percentages of $0.8 \%$ and $1 \%$ PALF.

From these results, the conclusion can be made that the addition of PALF in normal strength concrete reduces its compressive strength. This could be attributed to the adhesion properties due to the smooth texture of the PALF in the mix which reduces the bonding properties of the concrete mix and hence more compacting energy is required to achieve the desired compressive strength of the concrete. Therefore PALF cannot be used to enhance the compressive strength properties of normal weight concrete. 


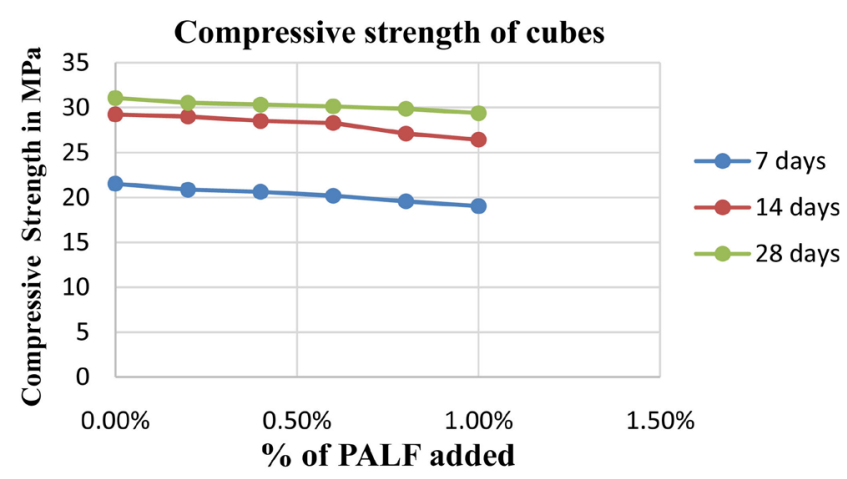

Figure 3. Effect of PALF on the compressive strength of concrete.

\subsection{Splitting Tensile Strength of Normal Strength Concrete with PALF}

The Splitting Tensile Strength at all percentages of PALF addition increased with curing time as 28 days at each percentage had a larger Splitting Tensile Strength value than those at 7 days and 14 days curing. There was a significant increment in the tensile splitting values at $1 \%$ PALF for 7 days, 14 days and 28 days curing times. There were percentage increment of $4.61 \%, 22.76 \%, 27.29 \%, 36.60 \%$ and $69.61 \%$ for $0.2 \%, 0.4 \%, 0.6 \%, 0.8 \%$ and $1 \%$ PALF additions respectively were obtained as compared to the control mix at 7 days curing time, where $3.15 \%$, $16.07 \%, 23.76 \%, 39.45 \%$, and $54.19 \%$ for $0.2 \%, 0.4 \%, 0.6 \%, 0.8 \%$ and $1 \%$ PALF additions respectively were obtained as compared to the control mix at 14 days testing, where $2.73 \%, 8.45 \%, 15.43 \%, 30.37 \%$, and $51.62 \%$ for $0.2 \%, 0.4 \%, 0.6 \%$, $0.8 \%$ and $1 \%$ PALF additions respectively were obtained as compared to the control mix at 28 days of curing time. Figure 4 shows graphically an improvement in the splitting tensile strength as the percentage of PALF were added therefore incorporating PALF as reinforced fibers on the Normal Strength Concrete can also improve first crack strength and ultimate ductility index.

\subsection{Flexural Strength Test on Normal Strength Concrete with PALF}

It was also observed that the flexural properties were improved comparing to the control mix of normal strength concrete as the percentage of PALF increased there was an increment of flexural strength value with curing time of 28 days. Results in Table 1 show that there was an improvement in the flexural values at $1 \%$ PALF. There were percentage increment of $0.98 \%, 3.54 \%, 10.84 \%, 15.06 \%$ and $42.58 \%$ for $0.2 \%, 0.4 \%, 0.6 \%, 0.8 \%$ and $1 \%$ PALF additions respectively were obtained as compared to the control mix at 28 days curing time, but it was observed as shown in Table 5 that the compaction factor was reduced as the percentage of PALF increased.

The PALF have increased the strength of the normal strength in tensile and flexure more than in compressive, this is showing that the PALF acted more in traction than in compression within the composite. 


\section{Tensile strength of cylinders}

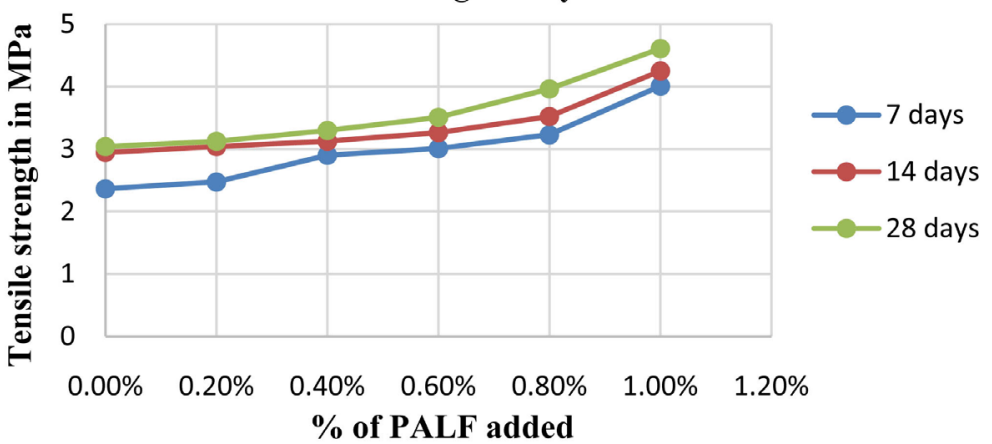

Figure 4. Effect of PALF on the splitting tensile strength of concrete.

Table 5. Effect of PALF on the flexural strength of concrete.

\begin{tabular}{ccccc}
\hline Batch & \% of PALF & Slump & Compacting factor & Flexural at 28 days \\
\hline 1 & $0.0 \%$ & $65 \mathrm{~cm}$ & 0.930 & $4.142 \mathrm{Mpa}$ \\
2 & $0.2 \%$ & $60 \mathrm{~cm}$ & 0.927 & $4.183 \mathrm{MPa}$ \\
3 & $0.4 \%$ & $55 \mathrm{~cm}$ & 0.920 & $4.289 \mathrm{MPa}$ \\
4 & $0.6 \%$ & $52 \mathrm{~cm}$ & 0.880 & $4.591 \mathrm{MPa}$ \\
5 & $0.8 \%$ & $40 \mathrm{~cm}$ & 0.850 & $4.766 \mathrm{MPa}$ \\
6 & $1.0 \%$ & $25 \mathrm{~cm}$ & 0.780 & $5.096 \mathrm{MPa}$ \\
\hline
\end{tabular}

\section{Conclusions}

From this experimental investigation, the following conclusions can be made:

1) PALF have shown that they can contribute to the construction field on Normal strength Concrete, they can reduce cracks in the structure and improve the tensile and flexure properties of NSC.

2) According to the experimental work, PALF reinforced NSC have a limitation when their percentages increase more than $1 \%$ of cement weight, the Normal Strength Concrete will not be workable.

3) The best percentage to be used is from $0.2 \%$ to $0.8 \%$ because it is where the slump was in range, it was found that PALF cannot be used to enhance compressive strength and water absorption.

\section{Recommendations}

From this experimental study, the following recommendations were made: For Possible Applications:

1) PALF can be utilized in Normal Strength Concrete to improve the split tensile strength and flexural strength in the production of structural of NSC especially where crack control is a concern especially in water retaining structures.

2) Further studies:

a) Investigations should be made on how to improve the bonding properties 
of the PALF reinforced Normal Strength Concrete.

b) The study at the durability aspect of PALF reinforced Normal Strength Concrete should also be studied.

\section{Conflicts of Interest}

The authors declare no conflicts of interest regarding the publication of this paper.

\section{References}

[1] Neville, A.M. (1995) Properties-of-Concrete-AM 149. 4th Edition, Addison Wesley Longman Ltd., Essex.

[2] Popovics, S. (1992) Concrete Materials Properties, Specifications and Testing. 2nd Edition, Noyes Publications, New Jersey.

[3] Mussig, J.J. (2010) Industrial Applications of Natural Fibres. Sivaraja, M. and Kandasamy, S. (2010) Characterisation of Natural Fibres as Concrete Composites for Structural Applications. International Journal of Materials and Product Technology, 36, 385-395.

[4] Wisittanawat, U., Thanawan, S. and Amornsakchai, T. (2014) Mechanical Properties of Highly Aligned Short Pineapple Leaf Fiber Reinforced-Nitrile Rubber Composite: Effect of Fiber Content and Bonding Agent. Polymer Testing, 35, 20-27. https://doi.org/10.1016/j.polymertesting.2014.02.003

[5] Daud, Z., Mohd, Hatta, M.Z.M., Kassim, A.S.M. and Aripin, A.M. (2014) Analysis of the Chemical Compositions and Fiber Morphology of Pineapple (Ananas comosus) Leaves in Malaysia. Journal of Applied Sciences, 14, 1355-1358.

[6] Ahad, N.A., Parimin, N., Mahmed, N. and Ibrahim, S.S. (2009) Effect of Chemical Treatment on the Surface of Natural Fiber. Journal of Liquid Chromatography \& Related Technologies, 6, 155-158.

[7] Odusote, J.K. and A.T.O. (2016) Mechanical Properties of Pineapple Leaf Fibre Reinforced Polymer Composites for Application as a Prosthetic Socket. Journal of Engineering Technology, 7, 125-139.

[8] Anbia Adam. and Yusri Yusof Adam. (2013) Review on PALF Extraction Machines and Its Properties Amongst Natural Fibers. University Tun Hussein Onn Malaysia (UTHM).

[9] Miur, C.E. (2013) Materials and Structures Engineering of NATURAL FIBERREINFORCED. Ph.D. Thesis, Department of Civil Engineering, University of Calabria, Italy, Cosenza.

[10] Pickering, K.L., Efendy, M.G.A. and Le, T.M. (2016) A Review of Recent Developments in Natural Fibre Composites and Their Mechanical Performance. Composites Part A: Applied Science and Manufacturing, 83, 98-112. https://doi.org/10.1016/j.compositesa.2015.08.038

[11] Munirah, M., Abdul Razak, R. and Hassan, A. (2007) Characterization and Treatments of Pineapple Leaf Fibre Thermoplastic Composite For Construction Application. Fakulti Kejuruteraan Kimia Dan Kejuruteraan Sumber Asli Universiti Teknologi Malaysia.

[12] Nounagnon A. Vodounon, Christopher Kanali and John Mwero (2018) Compressive and Flexural Strengths of Cement Stabilized Earth Bricks Reinforced with Treated and Untreated Pineapple Leaves Fibres. Open Journal of Composite Materials, 8, 145-160. 
[13] Da Costa, C.R., Del Curto, B. and Ritti, A. (2015) Mechanical and Chemical Characteristics of Vegetable Fibres, and Some Applications. 7 th International Textile, Clothing \& Design Conference, Dubrovnik, 5 October 2014, 4.

[14] Shetty, M.S. (2005) Concrete Technology Theory and Practice. India S. Chand \& Company Ltd., New Delhi.

[15] Riya, J. and Amritha, E.K. (2018) Experimental Study on Pineapple Leaf Fiber Reinforced RCC Beams. International Journal of Engineering Research and General Science, 6, 16. 